
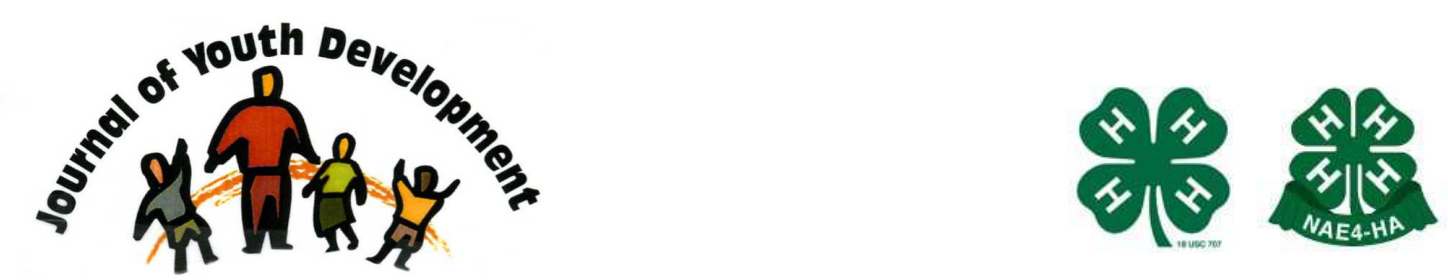

Bridging Research \& Practice

\title{
Community Interactive Processes and Rural Adolescents' Educational Achievement: Investigating the Mediating Effects of Delinquency and Self-Esteem
}

\author{
Omolola A. Adedokun \\ Department of Youth Development \& Ag. Education \\ Purdue University \\ West Lafayette, IN \\ oadedok@purdue.edu \\ Mark A. Balschweid \\ Department of Youth Development \& Ag. Education \\ Purdue University \\ West Lafayette, IN \\ markb@purdue.edu
}




\title{
JOURNAL OF YOUTH DEVELOPMENT \\ bridging research and practice

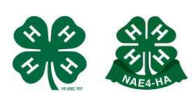

\section{Community Interactive Processes and Rural Adolescents' Educational Achievement: Investigating the Mediating Effects of Delinquency and Self-Esteem}

\author{
Omolola A. Adedokun and Mark A. Balschweid \\ Purdue University
}

\begin{abstract}
The study reported in this paper examines the effects of community interactive processes on rural adolescents' educational achievement. Specifically, the paper explored the direct effects of community interactive processes on rural adolescents' educational achievement and the indirect effects via self-esteem and delinquency. The method of structural equation modeling was used to analyze data from a nationally representative panel study of rural adolescent boys and girls in 10th grade through 12th grade. The results make a compelling case that communities are conduits for boosting self-esteem, facilitating normative behaviors and academic performance in rural adolescents.
\end{abstract}

\section{Introduction and Statement of the Problem}

There is an ancient traditional African proverb that "it takes a village to raise a child." This proverb highlights the belief of community researchers and youth development personnel that academically and behaviorally successful and self-confident youngsters are not only the products of strong families, but, also, the products of nurturing and supportive communities and neighborhoods (Coleman, 1988; Israel \& Beaulieu, 2004). Nowhere in America does this proverb hold more firm than in rural communities. Rural communities are characterized by unique social environments and social interactive processes that foster the formation and sustainability of effective social or communal networks (Crockett, Shanahan \& JacksonNewsome, 2000). Strong communal networks in-turn, facilitate the positive development and well being of children and adolescents (Israel \& Beaulieu, 2004).

Indeed, research has shown that compared to their urban counterparts, rural adolescents are characterized by a stronger sense of family and community, and the importance of connectedness and personal relationships (Bajema, Miller \& Williams, 2002; Burnell, 2003). Similarly, rural youth are more likely to be involved and committed to religious and other youth associations such as the 4-H and the National FFA organization (Chan \& Elder, 2001). 
Rural researchers (e.g., Israel \& Beaulieu, 2004; Israel, Beaulieu \& Hartless, 2001) have demonstrated that the strong interpersonal relationships and positive community interactive processes existing in rural communities are conduits for promoting positive youth development. With particular regard to academic achievement as an indicator of positive youth development, research has shown a positive link between community interactive processes and rural adolescents' academic achievement (Israel et al., 2001).

For example, social capital theorists (e.g., Coleman, 1988; Israel \& Beaulieu, 2004; Putnam, 2000 ) view the interactive processes in rural communities as social capital resources that facilitate and enhance rural adolescents' educational outcomes. That is, adolescents' and their families' integration into the rural community (e.g., monitoring of students' activities by nonfamily adult members of the community, participation in religious organizations and attendance at religious activities, participation in community activities, and, other forms of shared feelings of belonging) constitute social capital resources that facilitate rural adolescents' cognitive and behavioral development and well being (Coleman, 1988; Lin, 1999; Oorschot, Arts \& Glissen, 2006; Smith, Beaulieu \& Seraphine, 1995).

While much has been documented regarding the positive effects of community interactive processes on rural adolescents' educational outcomes, a notable limitation in extant studies is that little is known about the mechanisms through which community interactive processes affect rural adolescents' educational outcomes. That is, there is paucity of research on factors that mediate the effects of community interactive processes on educational achievement. In most of the available studies (e.g., Smith et al., 1995) the relationship between community interactive processes and rural adolescents' educational achievement are conceived as direct. However, there is the possibility that community interactive processes act through other factors in order to influence rural adolescents' educational achievement. Therefore, the effect might be indirect, or a combination of both direct and indirect influences.

A possible process by which community interactive processes may influence educational achievement is via their (interactive processes) potency in enhancing positive self-concept and inhibiting delinquent or non-normative behavior in adolescents (McNeal, 1999; Newman, 2004; Parcel \& Menaghan, 1993). However, these links have not been fully explored in educational and youth development research.

Given the observed limitation or gap in extant studies, the present study aims to investigate the mediating effects of self-esteem and delinquency on the relationship between community interactive processes and rural adolescents' educational achievement. It is hoped that the results of this study will provide further understanding and insight into delinquency and selfesteem as behavioral variables that may constitute sources of resilience for rural adolescents. Also, an understanding of self-esteem and delinquency as processes through which community interactive processes may influence rural adolescents' educational achievement and guide rural youth counselors and youth development personnel who focus on strategies of enhancing educational achievement.

\section{Literature Review}

\section{Community interactive processes and rural adolescents' educational achievement} Community interactive processes are the interactions taking place among members of a local community or neighborhood. These include family-community interactions, participation in 
community activities, neighbor-neighbor interactions, attendance at religious programs and other nurturing activities of communities, and the efforts of the community members in restraining improper behavior in young people (Israel et al., 2001; Smith et al., 1995).

Community interactive processes have been conceptualized differently in literature. For instance, Oorschot et al. (2006) contend that community interactive processes consist of three distinct but interrelated elements. First, social networks which refers to the links or connections an individual and his/her family have with other members of the local community, for example, involvement and participation in voluntary organizations, and, socializing with families and friends. The second element is social interactions which are described as the social relationships that exist among members of the community and their relations with the institutions of the community (Coleman, 1988). The third element, social integration refers to the extent to which adolescents and their families are socially embedded into their communities, or, the "structure of opportunities for social interaction" (Smith et al., 1995, p. 368).

For Israel et al. (2001), community interactive processes consist of two dimensions; community action and, individual relationships among adults and youths. Community action is characterized by many "actions and actors, inclusiveness of interests represented and widespread involvement in decision making and implementation" (Israel et al., 2001, p. 48). Community actions that may influence adolescents' educational aspirations and achievement include the availability of facilities such as sports arenas, schools, 4-H, FFA and other youth programs, and the opportunities for adolescents to be involved in volunteering and community development projects. The relationship dimension of the community interactive processes refers to the interpersonal relations that take place between adults and youth, and among the youth. For example, the interest of non-family adult members in the welfare of adolescents and the efforts of local religious organizations in involving children in youth programs that facilitate cognitive development (Israel et al., 2001).

Their different conceptualizations notwithstanding, these researchers, (i.e., Oorschot et al., 2006 and Israel et al., 2001) share the agreement that community interactive processes produce positive influences on rural adolescents' educational outcomes. When rural adolescents are involved in religious and other youth organizations (e.g. FFA, 4-H and youth bible study groups), they form relationships with peers and non-family adults from whom they can access useful information and other social resources that can positively influence their educational achievement (Coleman, 1988; Newman, 2004). In particular, the church often provides rural adolescents with opportunities to develop interactions with, and receive social support from adults outside of the family. For example, a Sunday school teacher may be able to provide basic moral teachings and other information that may shape adolescents' norms, values and educational aspirations, motivate them to shun delinquency, thereby increasing their chances of staying in school (Coleman, 1988; Israel et al., 2001; Israel \& Beaulieu, 2004).

Adolescents' interaction with the members of the community is not limited to their participation in religious and youth activities, but also includes their interactions with people in other social spheres such as on the streets, in the mall, schools, etc. As indicated by Morrow (2003) adolescents are "active social agents who, at least in the micro-level, shape the structures and processes around them" (p. 4). Hence, the way adolescents relate to wider social networks and communities have important influences on their educational outcomes. 
Parent-neighbor interactions are interactive processes that may influence rural adolescents' educational outcomes. An example of parent-neighbor interactions is parent-neighbor oversight (Bankston \& Zhou, 2002), or, watchful care which refers to the genuine care and interest of non-parent adults or neighbors in the academic progress and behavioral outcome of adolescents. This includes the willingness of neighbors to tell if they see another neighbor's child get into trouble, or do something wrong. Parent-neighbor oversight could also refer to the willingness of neighbors to respond to other neighbor's children in times of emergency (e.g., an accident), especially when the parents are absent. Coleman (1988) views practices such as parent-neighbor oversight as sources of social control that can serve to inhibit non-normative behavior in adolescence, hence exerting a positive influence on behavioral and educational outcomes.

\section{Self-Esteem, Delinquency and Educational Achievement}

As previously mentioned, community interactive processes may have indirect effects on educational achievement via boosting self-esteem and controlling delinquency and nonnormative behaviors in adolescents (McNeal, 1999). Both self-esteem and delinquency have been found to have significant influences on educational achievement (Garg et al., 2002; Trusty et al., 2003).

With regards to self-esteem, researchers have reported that students who have positive selfworth and self-evaluation are more likely to perform better in school than those who hold negative appraisals of themselves (Covington, 1989; Farmer, 1985; Marjoribanks, 2002; Owens, 1994). Covington (1989) found that as the level of self-esteem increases, the achievement scores of the students in his study increased. Similarly, Schmidt and Padilla (2003) found good academic performance to be linked with improvements in self-esteem. Turning to the relationship between delinquency and academic outcomes, research has documented that students who participate in delinquent behaviors score lower grades and are more likely to drop out of school (Chen \& Kaplan, 2003; Hill et al., 2004).

As suggested by literature (e.g., McNeal, 1999) self-esteem and delinquency could be mechanisms through which community interactive processes may influence educational achievement. For example, adolescents' participation in religious activities often serve as social controls of non-normative behaviors, thereby increasing the likelihood to stay in school and the possibility of college attendance (Hill et al., 2004; McNeal, 1999). Likewise, strong social support from members of the community results in fewer behavior problems, thereby facilitating the high levels of academic achievement (Hill \& Craft, 2003; Parcel \& Menaghan, 1993).

Similarly, positive social interactions within the rural community enhance adolescents' selfesteem (Dumont \& Provost, 1999; Kilpatrick, Bell \& Falk, 1999). Yabiku et al. (1999) explained that supportive social environments increases adolescents' positive self-image by building in them a sense that they are "cared for, esteemed, .., valued" loved, wanted and appreciated by others (Vedder, Boekaerts \& Seegers, 2005, p. 269). Community interactive processes also produce feelings of group solidarity and belonging, which in turn promotes the development of positive self worth in adolescents (Yabiku et al., 1999). That is, when adolescents feel the genuine concern of non-family adult members of the community they feel part of a "caring group, a group that is interested in their well-being" (Yabiku et al., 1999, p. 1501). 


\section{Hypotheses}

Using the literature reviewed as the backdrop, we developed and tested a structural model in which community interactive processes influence delinquency and self-esteem, which in turn influence rural adolescents' educational achievement. The specific hypotheses are two fold:

- First, community interactive processes will have a direct influence on rural adolescents' educational achievement.

- Second, community interactive processes will also have an indirect influence on rural adolescents' educational achievement via self-esteem and delinquency.

\section{Data and Methods}

Data Description

This study uses the first wave of data, collected between 1994 and 1995 by the National Longitudinal Study of Adolescent Health (Add Health), a nationally representative study conducted by the North Carolina Population Center. Add Health is a school-based cluster sample. The participating schools were selected from a sampling frame of American high schools sorted by region, level of urbanicity, school type, racial composition and size. In addition to interviewing the students, a parent or guardian of each student was also interviewed. See Bearman, Jones, \& Udry, (1997) for a detailed description of Add Health. Permission to use Add Health was obtained from the North Carolina Population Center and the Institutional Review Board at Purdue University.

The sample for this study consists of students in grades 10, 11 and 12 (Total=1657) enrolled in the 14 schools described as rural in the Add Health data set. However, since academic performance is an important outcome variable in this study, students $(n=18)$ who reported that their school did not give letter grades were excluded from the study because there was no way to calculate their GPA without their letter grades. Thus, the total number of participants was reduced to 1657, 36 percent of which are sophomores, 34 percent are juniors, and 30 percent are seniors. Also, 50.3 percent are boys while 49.7 percent are girls. About 81 percent of the students identified themselves as Caucasian, 14 percent as African Americans while the remaining 5 percent consists of other racial groups (e.g., Asians, Native Americans). The age of the students ranged from 15 to 20 years (mean age $=17.47$ ).

\section{Measurement of Variables}

\section{Community interactive processes}

The variable representing community interactive processes in this study is a latent construct measured by three indicators; first, parent-neighbor oversight, an additive scale consisting of the interviewed parents' responses to two items; (1) "if you saw a neighbor's child getting into trouble, would you tell your neighbor about it?" and, (2) "if a neighbor saw your child getting into trouble, would your neighbor tell you about it?" Response categories were "definitely would," "probably would," "might," "probably would not" and "definitely would."

The second indicator is adolescents' attendance at religious services which is a summated rating scale consisting of 2 items; "how often have you gone to religious services in the past year?" And, how often have you attended religious youth programs in the past year." Response categories included "once a week or more", "less than once a week, but at least once a month," "less than once a month" and "never"). Third is adolescents' interaction with members of the community which is a continuous variable created by adding students' responses to three "true or false" questions; "You know most of the people in your neighborhood," "in the past month, 
you have stopped on the street to talk with someone who lives in your neighborhood," and, "people in this neighborhood look out for each other."

\section{Delinquency}

Delinquency is a latent variable measured by three composite variables, each of which is a summated rating scale:

(1) a four item index of general delinquency (e.g., "in the past 12 months, how often did you damage any property?"), $a=0.65$

(2) six items of fighting and violence (e.g. "got into a physical fight") $a=0.81$, and,

(3) a three item index of stealing (e.g., "how often did you steal something worth less than $\left.\$ 50 ?^{\prime \prime}\right), a=0.78$.

The response categories ranged from "never" to "five or more times."

\section{Self-Esteem}

Self-esteem is a latent variable measured by four items very similar to Rosenberg's global selfesteem scale (Rosenberg, Schooler, \& Schoenbach, 1989). It thus, does not include items regarding specific attributes such as academic, body or social self-esteems. The students were asked to indicate how much they agreed or disagreed with the following statements: "You like yourself just the way you are," "you have a lot of good qualities," "you have a lot to be proud of," and, "you are just as good as other people." The answer categories ranged from strongly disagree to strongly agree.

\section{Educational Achievement}

Educational achievement is measured by each student's overall grade point average, GPA, calculated from their self-reported most recent English, history, science and mathematics classes.

Educational achievement was used as a latent construct with a single indicator (GPA). To achieve this, we assumed that GPA is a reliable measure of educational achievement.

\section{Control Variables}

The effects of race, age and parents' education on rural adolescents' educational achievement were controlled in the analysis.

\section{Data Analysis \\ Analytic Strategy}

The hypothesized model was tested with AMOS 6.0 (a structural equation modeling, SEM program), using covariance matrices and maximum likelihood estimation. Maximum likelihood estimation is a method used to estimate models with normally distributed endogenous variables. The descriptive statistics (See Table 1) shows that all the variables in this study are normally distributed with absolute values less than or equal to 3 for skewness and absolute values less than or equal to 10 for kurtosis as suggested by Livingston, (2004).

The method of structural equation modeling (SEM) is judged appropriate for this study because it is suited for analyses where the variables are latent constructs. In general, data analysis in SEM occurs in two stages. First, a factor analysis is conducted to investigate the loading of the measured indicators on the latent constructs, and, second, path analysis is conducted to investigate the structural relationship among the latent constructs (Kline, 2005). These stages are discussed in detail in the result section. 
Table 1

Descriptive Statistics of Indicators in the Model N=1657

\begin{tabular}{|l|l|l|l|c|}
\hline Variables & Mean & S.D & Skew & Kurtosis \\
\hline Parent-neighbor oversight & 8.35 & 1.37 & -0.92 & 1.25 \\
\hline Adolescents' attendance at religious services & 2.39 & 2.13 & 0.40 & -1.21 \\
\hline Adolescents' interaction within the community & 5.33 & 0.93 & -1.25 & 0.48 \\
\hline Educational achievement & 3.28 & 0.63 & -1.32 & 1.90 \\
\hline DELQ1 (4 items of general delinquency ) & 1.20 & 2.22 & 1.46 & 2.17 \\
\hline DELQ2 (6 items of fighting and violence) & 1.34 & 2.34 & 2.51 & 7.45 \\
\hline DELQ3 (3 items of stealing) & 0.70 & 1.59 & 2.97 & 9.27 \\
\hline SE1 ("just as good as other people") & 1.95 & 0.96 & -0.52 & -0.76 \\
\hline SE2 ("have lots of good qualities") & 4.24 & 0.64 & -0.59 & 0.93 \\
\hline SE3 ("have a lot to be proud of") & 4.23 & 0.71 & -1.01 & 2.05 \\
\hline SE4 ("like self as you are") & 3.91 & 0.95 & -0.82 & 0.24 \\
\hline Age & 17.47 & 0.95 & 0.12 & -0.53 \\
\hline Parents' education & 5.10 & 1.95 & 0.06 & 0.64 \\
\hline
\end{tabular}

S.D: Standard deviation

Model Identification, Assessment of Model Fit and Test of Significance of Direct and Indirect Effects

For proper analysis in AMOS, a specified model must be identified. That is, the degree of freedom ( $d f$ ) must be greater than zero (Arbuckle, 2005; Kline, 2005). As would be seen in the result section, the model estimated in this study had a positive and sufficient value. Likewise, the fit of the model was assessed by considering the model's RMSEA (Root Mean Square of Error Approximations), and fit indices, i.e., CFI (comparative fit index), IFI (incremental fit index), GFI (goodness of fit index), and NFI. According to Kline (2005), a non-significant chi square $(p>0.05)$ represents a good model fit. Likewise, reasonable RMSEA values are lower than or equal to 0.08 ., and, CFI, IFI, GFI and NFI values greater than 0.90 are adequate.

The AMOS program does not automatically include the standard errors or $p$-values of indirect effects in the output; hence the test of significance of indirect influences could be a problem. However, a researcher can overcome this difficulty by requesting AMOS to calculate the standard errors of indirect and mediating effects using the bootstrap method (Fan, 2003). The resulting output of bootstrap estimates in AMOS not only the standard errors and p-values of the total indirect effect, but, also the standard errors of each specific indirect effects. These values are then used to determine the significance of the indirect effects. For more on the bootstrap method see Fan (2003) and Preacher \& Hayes (2007). 


\section{Results}

The analysis of the model occurred in two stages. The first stage involved the estimation of a measurement model (i.e., confirmatory factor analysis), and the second stage involved the test of the structural model. A significant level of 0.05 was used as the threshold.

\section{Confirmatory Factor Analysis}

A measurement model (Figure 1) was estimated to ensure that the observed indicators loaded appropriately on the latent constructs. The fit indices (listed at the bottom of the figure) indicate that the data fits the model adequately well. Also, the model was sufficiently identified with a degree of freedom of 29. The loadings of the observed indicators on the latent constructs in the model are shown in Table 2, while the correlations among the constructs are shown in Table 3. The result shows that all factors have significant loadings on their respective latent constructs and all correlations among the constructs are significant.

Figure 1.

Measurement Model for Confirmatory Factor Analysis

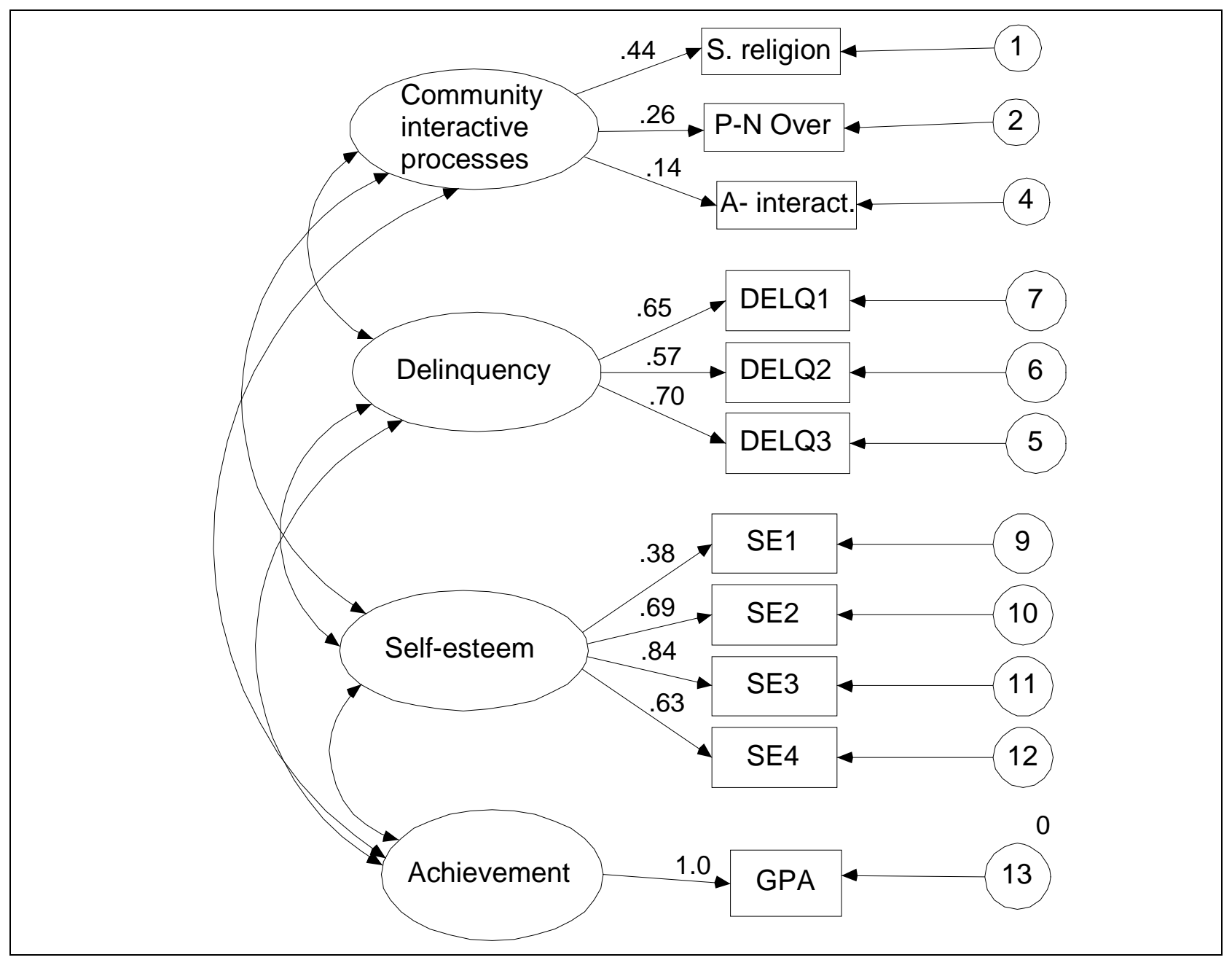

Fit Indices

$\chi^{2}=39, \mathrm{p}<.05 ; \mathrm{GFI}=0.98 ; \mathrm{NFI}=0.94$

$\mathrm{IFI}=0.96 ; \mathrm{CFI}=0.96 ; \mathrm{RMSEA}=0.04$ 
Table 2

Correlations among the Constructs

\begin{tabular}{|l|c|c|c|c|}
\hline & 1 & 2 & 3 & 4 \\
\hline 1. Delinquency & .00 & $-.11^{*}$ & $-.24^{*}$ & $-.18^{*}$ \\
\hline 2. Self-esteem & & .00 & $.40^{*}$ & $.17^{*}$ \\
\hline 3. Community interactive processes & & & .00 & $.32^{*}$ \\
\hline 4. Educational achievement & & & & .00 \\
\hline
\end{tabular}

$*=p<.05$

\section{Estimation of Structural Model}

This stage involved the examination of the mediating effects of self-esteem and delinquency on the relationship between community interactive processes and achievement. The statistical significance of all tested effects was determined using a p-value of 0.05 as the threshold. First, the direct effect of community interactive processes (without delinquency and self-esteem as mediators) was calculated by estimating the structural model in Figure 2 . The results revealed a significant effect of community interactive processes on educational achievement $(\beta=.22, p<$ $.05)$.

Figure 2

Direct effect of community interactive processed on educational achievement

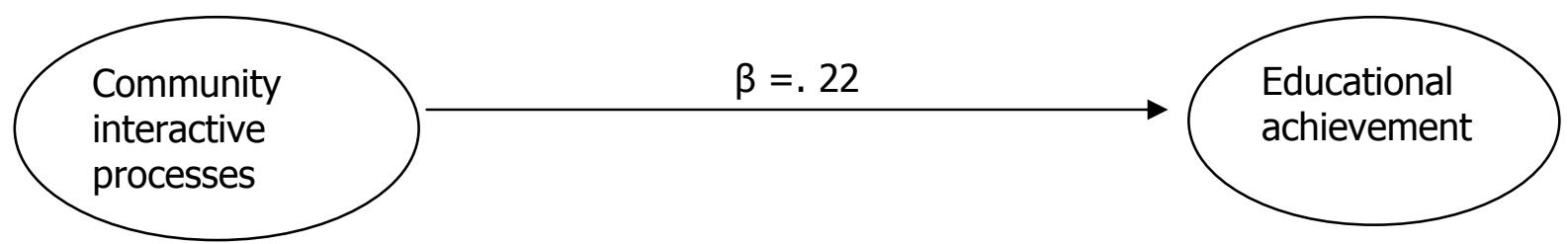

Next, we estimated the hypothesized model depicted in Figure 3 (with self-esteem and delinquency as multiple mediators of the relationship between community interactive processes and educational achievement). The fit indices of the model (listed at the bottom of the figure) suggest that the data fits the model adequately. 
Figure 3

Mediating effects of delinquency and self-esteem in the effects of community interactive processed on educational achievement

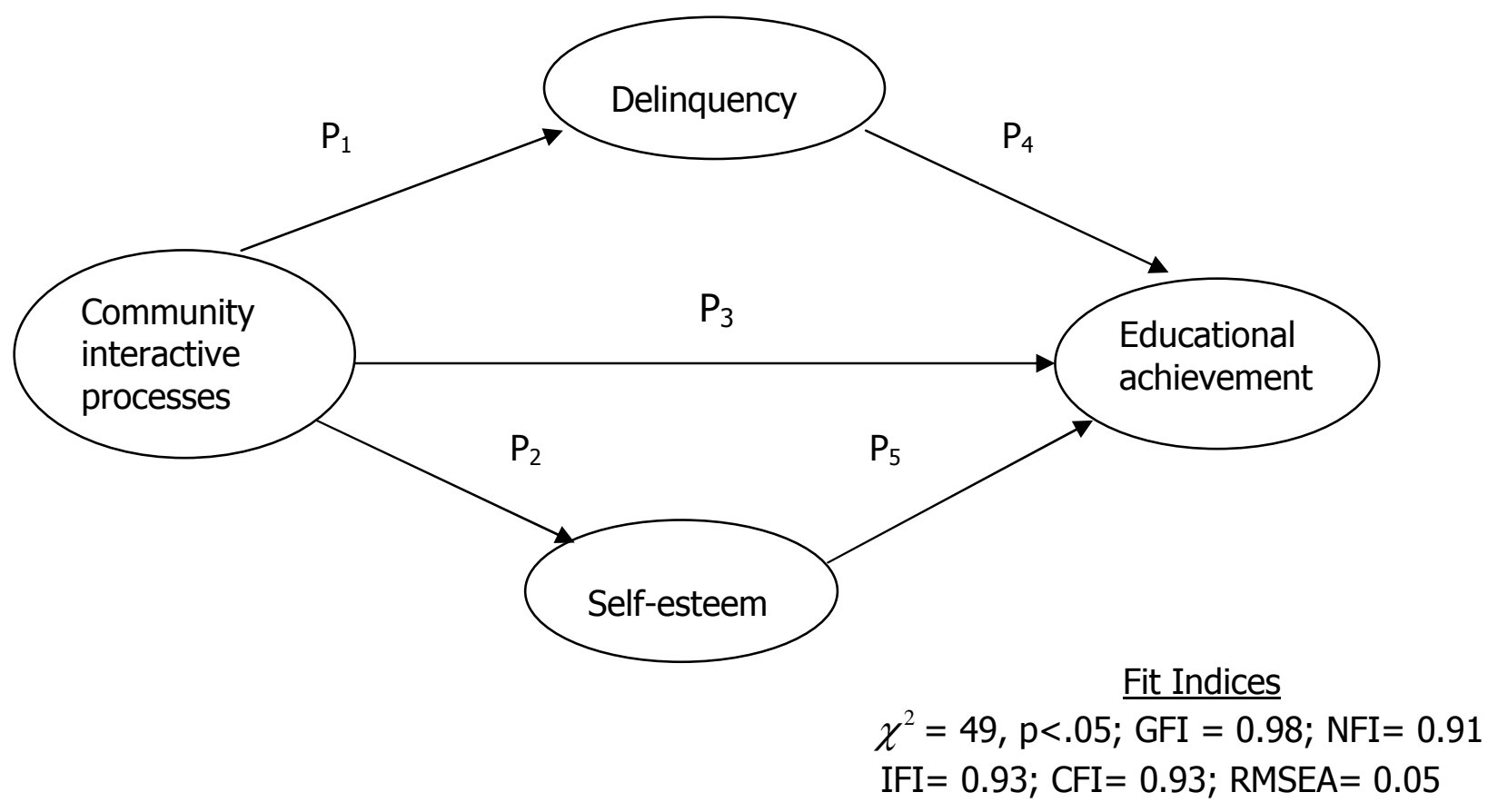

Table 3 contains the values of the estimated paths (i.e., $P_{1}, P_{2}, P_{3}, P_{4}$ and $P_{5}$ ). The result shows that community interactive processes significantly influenced delinquency $\left(P_{1}: \beta=-.28, p<.05\right)$ and self-esteem $\left(P_{2}: \beta=.27, p<.05\right)$. Also, the direct effect of community interactive processes on educational achievement $\left(P_{3}: \beta=.22, p<.05\right)$ was significant. Moreover, the direct effect of delinquency on educational achievement was significant $\left(\mathrm{P}_{4}: \beta=-.07, p<.05\right)$, while the direct effect of self-esteem on educational achievement was not significant $\left(P_{5}: \beta=.04, p>.05\right)$.

The total indirect effect of community interactive processes on educational achievement through delinquency and self-esteem $\left(P_{1} P_{4}+P_{2} P_{5}: \beta=.03, p>.05\right)$ was not significant. However, when multiple mediators are involved in a model, the focus is not only on the total indirect effect, but, also on the specific indirect effects through each mediator (Preacher \& Hayes, 2007). The analysis revealed that the specific indirect effect of community interactive processes via delinquency was significant $\left(\mathrm{P}_{1} \mathrm{P}_{4}: \beta=.02, p<.05\right)$ while the indirect effect through self-esteem $\left(\mathrm{P}_{2} \mathrm{P}_{5}: \beta=.01, p>.05\right)$ was not significant. The obvious reason for this is because the direct effect of self-esteem on educational achievement was not significant. The total effect of community interactive processes on educational achievement $\left(P_{3}+P_{1} P_{4}+P_{2} P_{5}: \beta\right.$ $=.22, p<.05$ ) was significant. 
Table 3

Coefficients of Estimated Paths $N=1657$

\begin{tabular}{|l|c|c|c|c|}
\hline Estimated Paths & $\begin{array}{c}\text { Un-standardized } \\
\text { Coefficient }(\beta)\end{array}$ & $\begin{array}{c}\text { Standard } \\
\text { Error }\end{array}$ & Critical Ratio & $\mathrm{p}$-value \\
\hline $\mathrm{P}_{1}$ & -.275 & .094 & 2.92 & $\mathrm{p}<.05$ \\
\hline $\mathrm{P}_{2}$ & .270 & .081 & 3.33 & $\mathrm{p}<.05$ \\
\hline $\mathrm{P}_{3}$ & .189 & .077 & 2.45 & $\mathrm{p}<.05$ \\
\hline $\mathrm{P}_{4}$ & -.072 & .031 & 2.32 & $\mathrm{p}<.05$ \\
\hline $\mathrm{P}_{5}$ & .041 & .063 & 0.65 & $\mathrm{p}>.05$ \\
\hline $\mathrm{P}_{1} \mathrm{P}_{4}$ & .020 & .009 & 2.22 & $\mathrm{p}<.05$ \\
\hline $\mathrm{P}_{2} \mathrm{P}_{5}$ & .011 & .055 & 0.20 & $\mathrm{p}>.05$ \\
\hline $\mathrm{P}_{1} \mathrm{P}_{4}+\mathrm{P}_{2} \mathrm{P}_{5}$ & .031 & .034 & 0.91 & $\mathrm{p}>.05$ \\
\hline $\mathrm{P}_{3}+\mathrm{P}_{1} \mathrm{P}_{4}+\mathrm{P}_{2} \mathrm{P}_{5}$ & .220 & .056 & 3.92 & $\mathrm{p}<.05$ \\
\hline
\end{tabular}

$\mathrm{P}_{1} \mathrm{P}_{4}$ is the specific indirect effect of community interactive processes on achievement through delinquency $P_{2} P_{5}$ is the specific indirect effect of community interactive processes on achievement through self-esteem

$\mathrm{P}_{1} \mathrm{P}_{4}+\mathrm{P}_{2} \mathrm{P}_{5}=$ the total indirect effect of community interactive processes on achievement through delinquency and self-esteem.

$P_{3}+P_{1} P_{4}+P_{2} P_{5}=$ the total effect (direct \& indirect) of community interactive processes on achievement.

\section{Discussion}

To recap, the present study explored self-esteem and delinquency as possible mediators of the relationship between community interactive processes and rural adolescents' educational achievement. In support of prior studies (e.g., Beaulieu et al., 2003), we found a significant positive direct link between community interactive processes and rural adolescents' educational achievement. The findings suggest that the social support that rural adolescents receive by attending religious services, their integration and interaction with other members of the community and parent-neighbor oversight facilitated their academic success.

The analysis revealed a significant negative effect of community interactive processes on delinquency. This finding lends some support to the position of previous studies (e.g., Coleman, 1988) that community interactive processes are social resources that may reduce or curb nonnormative behaviors in adolescents, thereby facilitating high levels of achievement. That is, rural adolescents' perceived social support from other members of the community produces feelings of group solidarity and belonging, and social acceptance, which promotes social compliance. We also found a significant inverse relationship between delinquency and educational achievement suggesting that delinquency reduces academic achievement, or, that social compliance enhances rural adolescents' educational achievement.

In addition, we found a significant positive link between community interactive processes and rural adolescents' self-esteem. This is consistent with the argument of Dumont and Provost (1999) that adolescents' participation in community activities and other forms of community interactive processes are social resources that facilitate positive self-worth. Hence, there is evidence to believe that rural adolescents' interaction and integration within the community promotes positive self-evaluation and self-appreciation. 
However, our hypothesis that self-esteem and delinquency would mediate the relationship between community social capital and educational achievement was only partially supported by the data. On one hand, we found the specific indirect effect of community interactive processes via delinquency to be significant, That is, delinquency mediates the relationship between community interactive processes and educational achievement. This suggests that adolescents' integration and participation in community interactive processes inhibit non-normative behavior, which in turn facilitates educational achievement. Our findings also lend support to the report of earlier studies that non-delinquent adolescents are likely to score higher grades than their delinquent peers (Chen \& Kaplan, 2003), and, that community interactive processes are social resources that inhibit deviant behaviors (Coleman, 1988).

On the other hand, we did not find a significant effect of self-esteem on educational achievement. In our study self-esteem does not mediate the relationship between community interactive processes and rural adolescents' educational achievement. Our finding is not consistent with Owens' (1994) position that adolescents with positive self-worth perform better in school than those with negative or low self-appraisals.

\section{Implications for Youth Stakeholders and Conclusion}

The findings of this the study make a compelling case that communities are conduits for boosting self-esteem, facilitating normative behaviors, and enhancing academic performance in rural adolescents. In addition, the study contributes to the understanding of the mechanisms of community interactive processes and their effect on rural adolescents' educational achievement. When rural communities provide nurturing environments for their adolescents, the reward is not only going to be academically successful youngsters, but also, self-confident, social-compliant and well behaved young people who can be trusted to take leadership positions.

Likewise, there are some implications for rural youth development workers and program planners (e.g., those interested in after-school programs) who are interested in programs and factors that can enhance adolescents' educational achievement. Youth development efforts at the community level may need to include programs that facilitate community interactive processes and serve as avenues to boost self-esteem and reduce delinquent behaviors in adolescents. Lastly, the study suggests that further research is needed to explore possible avenues through which community interactive processes affect rural adolescents' educational outcomes. For example, supportive community environments may decrease the incidents of psychological depression, thereby improving achievements.

This study is not without some limitations. For example, the analyses were limited to the full sample. Further studies might explore differences between boys and girls and among racial/ethnic groups and possible interaction between gender and race/ethnicity. The limitations notwithstanding, the results of this study reaffirm the important role of communities as vital influences on adolescent's behavioral and academic outcomes. In particular, the study suggests that disadvantages in community interactive processes and social capital resources make involvement in delinquency more possible, thereby hindering educational achievement. 


\section{References}

Arbuckle, J.L. (2005). Amos (Version 6.0) [Computer software]. Chicago: SPSS Inc.

Bajema, D.H., Miller, W.W., \& Williams, D.L. (2002). Aspirations of rural youth. Journal of Agricultural Education, 43(3) 1-11.

Bankston, C.L. III, \& Zhou, M. (2002). Social capital as a process: The meanings and problems of a theoretical metaphor. Sociological Inquiry, 72, 285-317.

Bearman, P.S., Jones, J., \& Udry, J.R. (1997). The national longitudinal study of adolescent health: Research design. Retrieved March 2007 from http://www.cpc.unc.edu/addhealth

Beaulieu, L.J., Israel, G.D., \& Wimberley, R.C. (2003). Promoting educational Achievement: A partnership of families, schools and communities. In D.L. Brown \& L.E. Swanson (Eds.), Challenges for rural America in the twenty-first century (pp. 273-289). University Park, PA: Pennsylvania State University Press.

Burnell, B.A. (2003). The "real world" aspirations of work-bound rural students. [Electronic version]. Journal of Research in Rural Education, 18, 104-113.

Chan, C.G., \& Elder, G.H. (2001). Family influences on the social participation of youth: The effects of parental social involvement and farming. Rural Sociology, 66, 22-42.

Chen, Z., \& Kaplan, H.B. (2003). School failure in early adolescence and status attainment in middle adulthood: A longitudinal study. Sociology of Education, 76, 110-127.

Coleman, J.S. (1988). Social capital in the creation of human capital. The American Journal of Sociology, 94(Suppl.), S95-S120.

Covington, M.J. (1989). Self-esteem and failure in schools: Analysis and policy implications. In A.M. Mecca, N.J. Smelser, \& J. Vasconcellos (Eds.), The social importance of self-esteem (pp. 72-124). Berkeley: University of California Press.

Crockett, L.J., Shanahan, M.J., \& Jackson-Newsom, J. (2000). Rural youth: Ecological and life course perspectives. In R. Montemayer, G.R. Adams, \& T.P. Gullotta, (Eds.), Adolescent diversity in ethnic, economic, and cultural contexts (pp. 43-74). Thousand Oaks, CA: Sage.

Dumont, M., \& Provost, M.A. (1999). Resilience in adolescents: Protective role of social support, coping strategies, self-esteem and social activities on experience of stress and depression. Journal of Youth and Adolescence, 28, 343-363.

Fan, X. (2003). Using commonly available software for bootstrapping in both substantive and measurement analyses. Educational and Psychological Measurement, 63; 24-50.

Farmer, H.S. (1985). Model of career and achievement motivation for women and men. Journal of Counseling Psychology, 32, 363-390.

Garg, R., Kauppi, C., Lewko, J., \& Urajnik, D. (2002). A Structural Model of Educational Aspirations. Journal of Career Development, 29, 87-108. 
Hill, N.E., \& Craft, S.A. (2003). Parent-school involvement and school performance: Mediated pathways among socio-economically comparable African American and Euro-American families. Journal of Educational Psychology, 95, 74-83.

Hill, N.E., Castellino, D.R., Lansford, J E., Nowlin, P., Dodge, K.A., Bates, J.E., et al. (2004). Parent academic involvement as related to school behavior, achievement and aspirations: Demographic variations across adolescence. Child Development, 75, 1491-1509.

Israel, G.D., \& Beaulieu, L.J. (2004). Investing in communities: Social capital's role in keeping youth in school: Journal of the Community Development Society, 34(2) 35-57.

Israel, G.D., Beaulieu, L.J., \& Hartless, G. (2001). The influence of family and community social capital on educational achievement. Rural Sociology 66, 43-68.

Kilpatrick, S., Bell, R., \& Falk, I. (1999). The role of group learning in building social capital. Journal of Vocational Education and Training, 51, 129144.

Kline, R.B. (2005). Principles and Practice of Structural Equation Modeling. $2^{\text {nd }}$ Edition. New York: Guilford Press.

Lin, N. (1999). Social networks and status attainment. Annual Review of Sociology, 25, 467487.

Livingston, E.H. (2004). The mean and standard deviation: What does it all mean? Journal of Surgical Research, 119, 117-123.

Marjoribanks, K. (2002). Family background, individual and environmental influences on adolescents' aspirations. Educational Studies, 28, (1), 33-46.

McNeal, R.B. (1999). Parental involvement as social capital: Differential effectiveness on science achievement, truancy, and dropping out. Social Forces, 78, 117-144.

Morrow, V. (2003, May). Conceptualizing social capital in relation to children and young people: Is it different for girls?Paper presented at the Gender and Social Capital Conference, Winnipeg, Canada.

Newman, J.L. (2004). Social capital and adolescent well-being in a national sample (Doctoral dissertation, University of California, Berkeley, 2004). Dissertation Abstracts International, 66, 761.

Oorschot, W., Arts, W., \& Glissen, J. (2006). Social capital in Europe: Measurement and social and regional distribution of a multifaceted phenomenon. Acta Sociologica, 49, 149-167.

Owens, T.J. (1994). Two dimensions of self-esteem: Reciprocal effects of self-worth and selfdeprecation on adolescent problems. American Sociological Review, 59, 391-407.

Parcel, T.L., \& Menaghan, E.G. (1993). Family social capital and children's behavior problems. Social Psychology Quarterly, 51,120-135. 
Preacher, K.J., \& Hayes, A F. (2007). Asymptotic and resampling strategies for assessing and comparing indirect effects in simple and multiple ediator models. Unpublished Manuscript, retrieved June 17, 2007 from http://www.comm.ohio-state.edu/ahayes/indirect2.pdf

Putnam, R.D. (2000). Bowling Alone: The Collapse and Revival of American Community, New York: Simon Schuster.

Rosenberg, M., Schooler, C., \& Schoenbach, C. (1989). "Self-Esteem and Adolescent Problems: Modeling Reciprocal Effects." American Sociological Review 54: 1004-18

Schmidt, J.A., \& Padilla, B. (2003). Self-esteem and family challenge: An investigation of their effects on achievement. Journal of Youth and Adolescence, 32, 37-46.

Smith, M.H., Beaulieu, L.J., \& Seraphine, A. (1995). Social capital, place of residence and college attendance Rural sociology, 60, 363-380.

Trusty, J., Plata, M., \& Salazar, C. (2003). Modeling Mexican Americans' educational aspirations: Longitudinal effects of variables across adolescence. Journal of Adolescent Research, 18, 131153.

Vedder, P., Boekaerts, M., \& Seegers, G. (2005). Perceived social support and well being in school: The role of students' ethnicity. Journal of Youth and Adolescence, 34, 269-278.

Yabiku, S.T., Axinn, W.G., \& Thornton, A. (1999). Family integration and children's self-esteem. American Journal of Sociology, 40, 1494-1524.

\section{Acknowledgement}

This research uses data from Add Health, a program project designed by J. Richard Udry, Peter S. Bearman, and Kathleen Mullan Harris, and funded by a grant P01-HD31921 from the Eunice Kennedy Shriver National Institute of Child Health and Human Development, with cooperative funding from 17 other agencies. Special acknowledgment is due Ronald R. Rindfuss and Barbara Entwisle for assistance in the original design. Persons interested in obtaining data files from Add Health should contact Add Health, Carolina Population Center, 123 W. Franklin Street, Chapel Hill, NC 27516-2524 (addhealth@unc.edu). No direct support was received from grant P01-HD31921 for this analysis.

(C) Copyright of Journal of Youth Development $~$ Bridging Research and Practice. Content may not be copied or emailed to multiple sites or posted to a listserv without copyright holder's express written permission. Contact Editor at: patricia.dawson@oregonstate.edu for details. However, users may print, download or email articles for individual use.

ISSN 2325-4009 (Print); ISSN 2325-4017 (Online) 